\title{
Contos de futebol escritos por mulheres: Entre as quatro linhas (2013), de Luiz Ruffato
}

\author{
Gustavo Cerqueira Guimarães \\ Universidade Federal de Minas Gerais, Belo Horizonte/Brasil \\ Doutor em Estudos Literários, UFMG \\ gustavocguimaraes@hotmail.com \\ [...] não me é fácil tomar partido em futebol - mas como \\ poderia eu me isentar a tal ponto da vida do Brasil? \\ Clarice Lispector, A descoberta do mundo.
}

Luiz Ruffato, um dos mais significativos escritores brasileiros da atualidade, nasceu em 1961, em Cataguases/MG, graduou-se em Comunicação pela Universidade Federal de Juiz de Fora e, atualmente, vive em São Paulo, onde se radicou desde os anos 1990. É autor de Eles eram muitos cavalos (2001), seu romance de estreia, vencedor do Troféu APCA e do Prêmio Machado de Assis, publicado na Itália, França, Alemanha, Argentina, Colômbia e em Portugal. Esse livro é composto de fragmentos que narram pequenas histórias que se passam em apenas um dia - "São Paulo, 9 de maio de 2000. Terça-feira". ${ }^{1}$ As vozes dessa narrativa são diversas, uma das características do gênero híbrido empregado, advindas de variados tipos de personagens - motorista, professor, camelô, mendigo, doméstica, cartomante - em seus prazeres e desprazeres diários.

Dentre outros livros, também publicou, Estive em Lisboa e lembrei de você (2009), Flores artificiais (2014), A história verdadeira do sapo Luiz (2014), estreia em literatura infantil, angariando o Prêmio Jabuti, De mim já nem se lembra (2016), O verão tardio (2019) e a pentalogia "Inferno provisório", que ficcionaliza a classe operária brasileira desde meados do século XX até o início do século XXI, composta por Mamma, son tanto felice (2005), O mundo inimigo (2005), Vista parcial da noite (2006), O livro das impossibilidades (2008) e Domingos sem Deus (2012), ganhador do Prêmio Casa de Las Américas.

\footnotetext{
${ }^{1}$ RUFFATO. Eles eram muitos cavalos, p. 13.
} 
Entre outros fatores, Ruffato se destaca atualmente no cenário literário por veicular o discurso das personagens brasileiras mais populares. Suas singulares narrativas incluem vez ou outra o tema do futebol, o qual aparece na sua forma mais essencial, como prática de lazer que propicia a convivência entre as pessoas, a exemplo de Zito, de $O$ mundo inimigo (2005), que conheceu sua namorada após a pelada da fábrica onde trabalhava, ${ }^{2}$ e do trecho de Eles eram muitos cavalos "[...] moleques jogam futebol no asfalto quente e bebês choram em alguma janela e marido e mulher pais e filhos e babéis abafadas na televisão-a-cabo estranhezas filtradas do apartamento de cima móveis deslocados uma bolinha de gude". ${ }^{3}$

Outro lugar de destaque que o escritor mineiro ocupa é o de organizador de mais de uma dezena de coletâneas, todas elas preocupadas em promover os discursos silenciados pelo padrão machista, racista, heteronormativo e burguês da sociedade, como 25 mulheres que estão fazendo a nova Literatura Brasileira (2005), Entre nós: contos sobre homossexualidade (2007) e Questão de pele: contos sobre preconceito racial (2009), cujos títulos são autoexplicativos, e Nos idos de Março (2014), livro composto de 18 contistas que denunciaram o regime ditatorial brasileiro à época, tais como Roberto Drummond, Sérgio Sant'Anna, Nélida Piñon, João Gilberto Noll e Wander Piroli.

Nesse sentido, como escritor e antologista, Ruffato procurou contribuir um pouco para o estreitamento da relação entre a literatura e o futebol, demonstrando seu esforço para promover originais histórias do "povo" em contato com o jogo, sobretudo ao organizar a antologia Entre as quatro linhas: contos sobre futebol (2013). Além disso, suas escolhas buscaram "oferecer uma amostra da complexidade territorial e cultural de um país tão vasto como intangível quanto o Brasil”, 4 contemplando diversas gerações, regiões, locais de moradia e gênero, sendo nove escritores e seis destacadas escritoras a tramar sobre o jogo, contribuindo sensivelmente para promover a atividade das mulheres em espaços pelos quais elas mal transitavam - Eliane Brum (1966), "Raimundo, dono da bola"; Adriana Lisboa (1970), "O sucesso"; Carola Saavedra (1973), "Reverso do jogo"; Tércia Montene-

\footnotetext{
${ }^{2}$ RUFFATO. O mundo inimigo, p. 141-142.

${ }^{3}$ RUFFATO. Eles eram muito cavalos, p. 76.

${ }^{4}$ RUFFATO. Entre as quatro linhas, p. 11.
} 
gro (1976), "Quatro linhas"; Ana Paula Maia (1977), "Cemitério clandestino"; e Tatiana Salem Levy (1979), "Um dia, uma camisa". 5 Afinal, vale a pena nos perguntarmos juntamente com as recentes indagações de Silvana Goellner, uma das principais pesquisadoras do assunto,

Por que incomoda tanto a presença da mulher nas diferentes dimensões do futebol? 0 que elas desestabilizam? Que discursos fissuram? Por que precisam ser negligenciadas ou sub-representadas nesse campo? Que espectros evocam? [...] Não há outra razão para tal ostracismo senão o fato de que a presença das mulheres no futebol destitui poderes, inclusive daqueles que se julgam autorizados a dizer o que elas podem ou não vivenciar dentro da modalidade. ${ }^{6}$

Segundo Cláudia Piñeiro, no prólogo da antologia argentina de contos sobre futebol escritos por mulheres, "o futebol é território de homens. E se uma mulher se atreve a pisar nesse território, deverá suportar a desconfiança, a subestimação e algum desconforto por participar de uma festa que não foi convidada". ${ }^{7}$

Assim, dois pontos são curiosos de observar nesse conjunto de contos escritos por mulheres selecionados por Ruffato. Um deles é o fato de a prática do futebol ser protagonizada por mulher em apenas um dos contos, em "O sucesso", de Adriana Lisboa. Nele, a bola é jogada na rua por duas garotinhas. No entanto, o jogo é explorado ao longo da narrativa mais como uma estratégia de aproximação entre meninas e meninos.

[Eles se] encostaram no poste de luz da esquina, ficaram ali. [...] As duas se empertigaram. Peitos se estufaram para parecer mais desenvolvidos do que eram. Risadas altas viraram pura estratégia experimental de sedução. [...] 0 sol castigava e a rua de paralelepípedos estava longe de ser o palco ideal para a demonstração de intimidade com a bola, mas elas faziam o possível. Seu pensamento era idêntico: será que os dois garotos [...] querem jogar também? [...] Sem desviar os olhos em nenhum momento para os garotos apoiados no poste de luz, elas os encorajavam com a força magnética de sua excitação. ${ }^{8}$

Por um lado, o conto parece reforçar a ideia já preestabelecida de que o campo de futebol não é um espaço para "as meninas". E, por outro lado, na melhor das

\footnotetext{
${ }^{5}$ Para um maior aprofundamento sobre a contextualização das antologias de contos sobre futebol no Brasil, conferir: GUIMARÃES. Inventariar contos sobre futebol: o estrangeiro e a mulher nas antologias brasileiras, 2017.

${ }^{6}$ GOELLNER. Apresentação, p. 14-15.

${ }^{7}$ PIÑEIRO. Las dueñas de la pelota, p. 12. (Tradução livre).

${ }^{8}$ LISBOA. O sucesso, p. 108.
} 
hipóteses, o conto denuncia, de modo irônico, a maneira ultrajante empregada pelos meninos para possuírem a bola, pois, "com surpreendente desenvoltura e nenhuma timidez", eles agarraram a bola e saíram em disparada. "Eles levaram a bola". ${ }^{9}$

0 outro ponto bastante interessante é perceber que nesse conjunto de con-

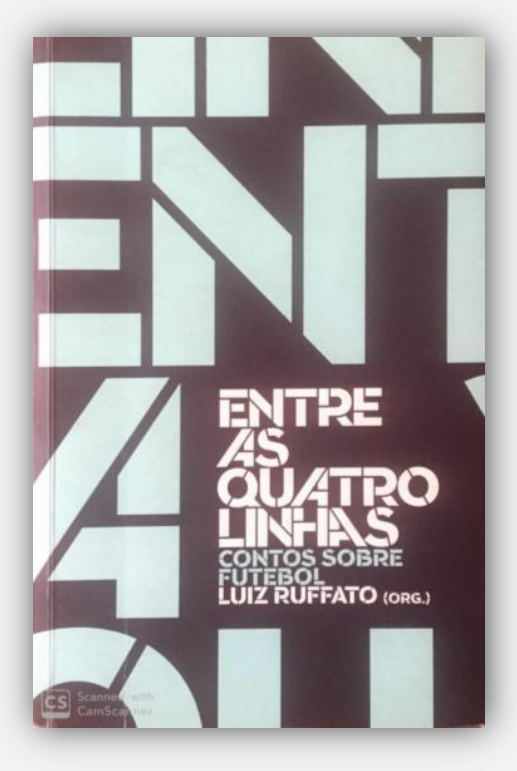
tos escritos por mulheres, o futebol é apenas o pano de fundo para o desenvolvimento de relações amorosas. Nesses casos, o futebol é introduzido como um antagonista, um rival, das personagens femininas, pois os companheiros, praticantes do jogo, atribuem mais importância ao esporte do que ao relacionamento, resultando em sentimentos adversos da parte delas, como a inconformidade, o ciúme e a insatisfação. Isso é marcante, por exemplo, nos contos "Quatro linhas", de Tércia Montenegro, e no extraordinário conto de Tatiana Salem Levy, "Um dia, uma camisa", um dos mais bem acabados, sem dúvida alguma.

No primeiro deles, a narradora constata que a relação que o namorado tem com o futebol beira o fervor religioso, expondo abertamente sua insatisfação: "Eu me enjaulava, fingindo produzir arte enquanto os homens da casa cumpriam a bestial adoração do esporte. Estava sufocando por ser tão ignorada, sentindo-me explodir no instante em que puxei meu namorado durante os comerciais e lhe disse uma dureza, com os olhos engasgados de lágrima". ${ }^{10}$ Ao longo do conto, percebe-se o processo de desintegração da relação por conta da intensa energia que o namorado dispensa ao futebol.

Já, em "Um dia, uma camisa" é mostrado subliminarmente o relacionamento homoafetivo de Francisco e Jordi. A amizade deles se desenvolve através do amor que ambos têm pelo futebol. Francisco, embora seja casado com Dalva, demonstra mais afeto por Jordi do que por ela. Em um dos dias em que a esposa vai assistir ao jogo do marido, "ele se aproximou [dela] no intervalo, o corpo melado de tanto suor, ela teve a certeza de que o jogo de futebol era um sinal. Jordi, uma maldição".11

\footnotetext{
${ }^{9}$ LISBOA. O sucesso, p. 109.

${ }^{10}$ MONTENEGRO. Quatro linhas, p. 121.

${ }^{11}$ LEVY. Um dia, uma camisa, p. 92.
} 
De todo modo, por mais que a prática e os temas futebolísticos representados na literatura brasileira sejam majoritariamente pelo viés masculino, uma coisa parece certa: a melhor maneira de continuar desestabilizando a hegemonia nesse terreno é justamente preenchendo os espaços que tradicionalmente foram ocupados por eles. Entenda-se por espaços, os locais onde também circulam os discursos da mídia e do campo editorial, que se relacionam entre si e dramatizam aspectos socioculturais da vida contemporânea, por vezes tão hostis à presença da mulher. Ocupar igualmente os espaços de protagonismo dentro das narrativas sobre futebol, talvez seja mais um significativo passo para equiparar esse jogo.

\section{REFERÊNCIAS}

GOELLNER, Silvana Vilodre. Apresentação. In: KESSLER, Cláudia Samuel (org.). Mulheres na área: gênero, diversidade e inserções no futebol. Porto Alegre: Editora da UFRGS, 2016, p. 13-15.

GUIMARÃES, Gustavo Cerqueira. Inventariar contos sobre futebol: o estrangeiro e a mulher nas antologias brasileiras. Aletria: Revista de Estudos de Literatura, v. 26, n. 3, p. 87-121, abr. 2017.

LEVY, Tatiana Salem. Um dia, uma camisa. In: RUFFATO, Luiz (org.). Entre as quatro linhas: contos sobre futebol. São Paulo: Editora DSOP, 2013, p. 89-103.

LISBOA, Adriana. O sucesso. In: RUFFATO, Luiz (org.). Entre as quatro linhas: contos sobre futebol. São Paulo: Editora DSOP, 2013, p. 105-111.

MONTENEGRO, Tércia. Quatro linhas. In: RUFFATO, Luiz (org.). Entre as quatro linhas: contos sobre futebol. São Paulo: Editora DSOP, 2013, p. 117-124.

PIÑEIRO, Claudia. Las dueñas de la pelota: cuentos de fútbol escritos por mujeres. Buenos Aires: El Ateneo, 2014.

RUFFATO, Luiz. (Org.). Entre as quatro linhas: contos sobre futebol. São Paulo: Editora DSOP, 2013.

RUFFATO, Luiz. O mundo inimigo. Rio de Janeiro: Record, 2005.

RUFFATO, Luiz. Eles eram muitos cavalos. Rio de Janeiro: Record, 2012 [2001]. 